\title{
Article \\ Optimizing Dose and Timing in Magnetic Tracer Techniques for Sentinel Lymph Node Detection in Early Breast Cancers: The Prospective Multicenter SentiDose Trial
}

\author{
Abdi-Fatah Hersi ${ }^{1,2, *}$, Lida Pistiolis ${ }^{3}$, Carlos Dussan Luberth ${ }^{4}$, Eva Vikhe-Patil ${ }^{4}{ }^{\oplus}$, Fredrik Nilsson ${ }^{5}$, \\ Imad Mohammed ${ }^{6}$, Roger Olofsson Bagge ${ }^{3}$, Fredrik Wärnberg ${ }^{3,7}$, Staffan Eriksson ${ }^{1,2, \dagger}$ \\ and Andreas Karakatsanis $7,+$ (i)
}

check for updates

Citation: Hersi, A.-F.; Pistiolis, L.; Dussan Luberth, C.; Vikhe-Patil, E.; Nilsson, F.; Mohammed, I.; Olofsson Bagge, R.; Wärnberg, F.; Eriksson, S.; Karakatsanis, A. Optimizing Dose and Timing in Magnetic Tracer Techniques for Sentinel Lymph Node Detection in Early Breast Cancers: The Prospective Multicenter SentiDose Trial. Cancers 2021, 13, 693. https://doi.org/10.3390/cancers1304 0693

Academic Editor:

Gilles Houvenaeghel

Received: 1 December 2020

Accepted: 5 February 2021

Published: 9 February 2021

Publisher's Note: MDPI stays neutral with regard to jurisdictional claims in published maps and institutional affiliations.

Copyright: (c) 2021 by the authors. Licensee MDPI, Basel, Switzerland. This article is an open access article distributed under the terms and conditions of the Creative Commons Attribution (CC BY) license (https:/ / creativecommons.org/licenses/by/ $4.0 /)$.
1 Centre for Clinical Research, Region Västmanland-Uppsala University, Sigtunagatan, 72189 Västerås, Sweden; staffan.eriksson@regionvastmanland.se

2 Department of Surgery, Västmanlands Hospital, Sigtunagatan, 72189 Västerås, Sweden

3 Department of Surgery, Institute of Clinical Sciences, Sahlgrenska Academy at University of Gothenburg, Sahlgrenska University Hospital, 41345 Gothenburg, Sweden; lida.pistioli@vgregion.se (L.P.); roger.olofsson.bagge@vgregion.se (R.O.B.); fredrik.warnberg@surgsci.uu.se (F.W.)

4 Department of Surgery, Linköping University Hospital, 58185 Linköping, Sweden; carlos.dussan.luberth@regionostergotland.se (C.D.L.); eva.vikhe.patil@regionostergotland.se (E.V.-P.)

5 Department of Surgery and Perioperative Sciences, Umeå University Hospital, 90187 Umeå, Sweden; fredrik.nilsson@umu.se

6 Department of Surgery, Kalmar County Hospital, 39185 Kalmar, Sweden; imad.mohammed@ltkalmar.se

7 Department of Surgical Sciences, Uppsala University, Akademiska Sjukhuset, 75185 Uppsala, Sweden; andreas.karakatsanis@surgsci.uu.se

* Correspondence: abdi-fatah.hersi@regionvastmanland.se

+ Staffan Eriksson and Andreas Karakatsanis share last authorship.

Simple Summary: Superparamagnetic iron oxide (SPIO) nanoparticles have comparable performance to the combination of radioisotope and blue dye (RI + BD) for sentinel lymph node (SLN) biopsy in breast cancer. In this multicenter prospective study, lower SPIO doses (undiluted 1.5 vs. $1.0 \mathrm{~mL}$ ) in different timeframes (perioperative vs. 1-7 days preoperative) and injection sites (subareolar vs. peritumoral) were compared to the previous standard (diluted $2.0 \mathrm{~mL}$ perioperatively) from the earlier Nordic trial. RI + BD were co-administered as background. In total, 534 patients were analyzed. SPIO SLN detection rates were similar $(97.5 \%$ vs. $100 \%$ vs. $97.6 \%, p=0.11$ ) and respectively non-inferior to the dual technique. Significantly more SLNs were retrieved in the preoperative $1.0 \mathrm{~mL}$ cohort compared with $1.5 \mathrm{~mL}$ and the Nordic cohorts ( 2.18 vs. 1.85 vs. $1.83, p=0.003$ ). Thus, SPIO at 1.5 and $1.0 \mathrm{~mL}$ was non-inferior to both Sienna $+{ }^{\circledR}$ and the dual technique for SLN detection.

Abstract: Superparamagnetic iron oxide nanoparticles (SPIO) are non-inferior to radioisotope and blue dye $(\mathrm{RI}+\mathrm{BD})$ for sentinel lymph node (SLN) detection. Previously, $2 \mathrm{~mL}$ SPIO (Sienna ${ }^{\circledR}$ ) in $3 \mathrm{~mL} \mathrm{NaCl}$ was used. In this dose-optimizing study, lower doses of a new refined SPIO solution (Magtrace $\left.{ }^{\circledR}\right)(1.5 \mathrm{vs} .1 .0 \mathrm{~mL}$ ) were tested in different timeframes ( $0-24 \mathrm{~h}$ perioperative vs. 1-7 days preoperative) and injections sites (subareolar vs. peritumoral). Two consecutive breast cancer cohorts $(n=328)$ scheduled for SLN-biopsy were included from 2017 to 2019. All patients received isotope \pm blue dye as back-up. SLNs were identified primarily with the SentiMag ${ }^{\circledR}$ probe and thereafter a gamma-probe. The primary endpoint was SLN detection rate with SPIO. Analyses were performed as a one-step individual patient-level meta-analysis using patient-level data from the previously published Nordic Trial $(n=206)$ as a third, reference cohort. In 534 patients, the SPIO SLN detection rates were similar $(97.5 \%$ vs. $100 \%$ vs. $97.6 \%, p=0.11)$ and non-inferior to the dual technique. Significantly more SLNs were retrieved in the preoperative $1.0 \mathrm{~mL}$ cohort compared with 1.5 and the $2.0 \mathrm{~mL}$ cohorts $(2.18$ vs. 1.85 vs. $1.83, p=0.003$ ). Lower SPIO volumes injected up to 7 days before the operation have comparable efficacy to standard SPIO dose and RI + BD for SLN detection.

Keywords: sentinel lymph node biopsy; breast cancer; superparamagnetic iron oxide; magnetic tracer; sentinel lymph node 


\section{Introduction}

Sentinel lymph node biopsy (SLNB) is the standard axillary staging method in patients with breast cancer without clinically evident nodal spread [1] and is associated with similar oncologic outcomes but less morbidity than conventional axillary lymph node dissection (ALND) [2-5]. Traditionally, detection with a radioisotope tracer (RI) combined with blue dye (BD), with a detection rate of more than $95 \%$, has been regarded gold standard [1,6-8]. This method of combining tracers is known as the "dual technique". However, several drawbacks such as limited access, rigid legislation on radioactive disposal, short half-life of RI [9] as well as anaphylactic reactions and skin staining at the injection site related to the use of BD $[10,11]$ limit its usage.

Superparamagnetic iron oxide nanoparticles (SPIO) are a SLNB tracer with comparable detection rates as the dual technique but provide logistical advantages such as increased flexibility in the timeframe of administration [12-14]. An earlier version (Sienna $+{ }^{\circledR}$, Endomagnetics Ltd., Cambridge, UK) required dilution (2 $\mathrm{mL} \mathrm{SPIO}+3 \mathrm{~mL} \mathrm{NaCl} 0.9 \%)$. Adverse effects included patient discomfort, artifacts on magnetic resonance imaging (MRI) and brown skin staining $[15,16]$. Previous reports indicated higher detection rates if SPIO was injected 1-28 days before surgery, instead of on the day of surgery $[14,17,18]$. Recently, a new solution of SPIO (Magtrace ${ }^{\circledR}, 2 \mathrm{~mL}$, Endomagnetics Ltd.) with no need for dilution, has been shown to be noninferior to the dual technique $[19,20]$.

The aim of this study was to compare the SLN detection rate using Magtrace ${ }^{\circledR}$ at lower doses, with different timeframes and injection sites, and to investigate whether they were noninferior to the previous SPIO solution of Sienna $+{ }^{\circledR}$.

\section{Methods}

This multicenter prospective trial enrolled patients scheduled for primary breast surgery including SLNB at six Swedish centers. Inclusion criteria were breast cancers graded $\mathrm{cT}_{0-2} \mathrm{cN}_{0} \mathrm{CM}_{0}$, and Eastern Cooperative Oncology Group (ECOG) performance status $0-2$. All patients provided oral and written consent. Patients with previous ipsilateral breast or axillary surgery and/or radiation and neoadjuvant chemotherapy were excluded. The dataset of the Nordic SentiMag trial [13] was used to derive reference values and for subsequent patient-level comparisons. The study was approved by the Uppsala University regional ethics committee (Decision Number 2017/063), registered in a prospective database (ISRTCN11156955) and monitored by an independent external agency.

\subsection{Procedure}

Magtrace ${ }^{\circledR}$ was administered in two different sequential settings: the first patient cohort received a periareolar injection of $1.5 \mathrm{~mL}$ SPIO on the day of surgery, not later than $20 \mathrm{~min}$ prior to the start of surgery, followed by a five minute massage. The second patient cohort received $1.0 \mathrm{~mL}$ SPIO by subareolar or peritumoral injection into the interstitial tissue without massage, 1-7 days before surgery. All patients received RI and BD, according to routine practice.

During surgery, the surgeon initially used the Sentimag ${ }^{\circledR}$ (Endomagnetics Ltd.) to localize the SLN and then used the gamma probe to confirm this, both before and after skin incision. All SLNs detected intraoperatively with the Sentimag ${ }^{\circledR}$, gamma probe or stained brown or blue were excised. The conventional cut-off of $10 \%$ of the SLN with the highest signal (SPIO or RI) was implemented. After excision, ex vivo counts for each lymph node with both probes were registered. SLN status was assessed by routine histopathology.

\subsection{Sample Size Calculation, Statistical Analysis and Data Collection}

The main objective was to evaluate whether administration of Magtrace ${ }^{\circledR}$ as described above was non-inferior to Sienna $+{ }^{\circledR}$ for SLN detection. We used the earlier detection rate of $97 \%$ with Sienna $+{ }^{\circledR}$ from the Nordic trial [13] and defined a non-inferiority margin of $4 \%$, resulting in a lower threshold of $93 \%$, to declare non-inferiority. For this, a sample size of 150 per cohort with a minimum of 146 successful magnetic SLNB procedures was required, 
to ensure that the lower $95 \%$ confidence interval of the detection rate proportion would still be $>93 \%$. Allowing for a 10\% dropout rate, 165 patients were required in each cohort. Detection rate per patient was additionally tested in a right-sided binominal test with the alternative hypothesis that the proportion of successful SLNBs would be $>0.93$ for each tracer. A $p$-value of $<0.05$ would indicate that the null hypothesis was rejected. To allow for direct comparisons and to define factors affecting outcomes, patient-level data from the Nordic trial [13] were used as a third, reference cohort and comparisons were performed as a one-step individual patient data (IPD) meta-analysis [21].

Demographic and clinical patient data, tumor characteristics, intraoperative magnetic and radioisotope signals, SLN-specific data, tracer-specific data, pre/postoperative histopathological data, possible adverse events and postoperative staining were recorded.

The primary endpoint was the proportion of successful magnetic SLN procedures divided by the total number of SLN procedures performed (detection rate per patient). A procedure was defined as successful for the respective tracer if at least one SLN was identified and retrieved. Secondary endpoints were (a) nodal detection rate, defined as the number of magnetic SLNs identified, divided with the number of SLNs detected with both modalities, (b) the average number of excised SLNs per patient, (c) the proportion of pathologically positive SLNs per patient and per node (malignancy rate) and (d) the SPIO-RI SLN concordance rate per patient and per node, defined as the proportion of patients or nodes detected by both SPIO and RI to the patients or nodes detected by RI.

All endpoints were analyzed at two different cut-off points with regards to the Sentimag ${ }^{\circledR}$ signal of the SLN, $>0$ and $>20$. The latter was selected to adjust for overlapping of detection methods (RI vs. SPIO), as nodes with low signal on one probe and high on the other, while formally considered as SLNs detected with both methods, would probably not have been identified had the patient received only one tracer.

The manuscript was prepared according to the "Strengthening the Reporting of Observational Studies in Epidemiology" (STROBE) statement [22], and the Preferred Reporting Items for Systematic Review and Meta-Analyses of individual participant data (the PRISMA-IPD) statement was followed for database formation and statistical analyses [23]. Subsequently, any differences in study design or inclusion criteria between the SentiDose protocol and the Nordic trial protocol were parametrized as independent input variables, to allow for harmonization of definitions and the conduct of multivariable regression analyses, as appropriate. This resulted in an individual patient-level dataset comprising of the Nordic trial population (retroareolar/interstitial injection of $2 \mathrm{~mL}$ Sienna+ ${ }^{\circledR}$ (Endomagnetics Ltd.) diluted with $3 \mathrm{~mL}$ of $\mathrm{NaCl} 0.9 \%$ or local anesthetic, administered perioperatively) used as a historic reference and the two prospectively collected cohorts of the SentiDose trial, as described above.

Comparisons of numeric outcomes were performed by one-way analysis of variance (ANOVA), whereas dichotomous outcomes were analyzed by means of Pearson's $\chi^{2}$. Bonferroni adjustment for multiple comparisons was performed. Multivariable regression was performed if univariable associations with $p<0.1$ were detected among clinically relevant variables. Background within-patient comparisons between SPIO and RI \pm BD were performed to ensure non-inferiority and patient safety, but were not intended in the statistical analysis plan and thus, the published endpoints of the Nordic trial were not repeated.

\subsection{Staining}

All patients were prospectively followed for postoperative skin staining by SPIO or BD. Herein, patients with a brown/grey skin discoloration up to 6 months post-surgery were recorded. Long-term follow-up will be reported elsewhere.

\section{Results}

Consecutive patients were recruited, with the $1.5 \mathrm{~mL}$ cohort $(n=165)$ completed between August 2017 and April 2018 and the $1.0 \mathrm{~mL}$ cohort $(n=165)$ between May 2018 
and September 2019. Protocol violation led to the exclusion of two patients from the $1.5 \mathrm{~mL}$ cohort. In total, 534 patients were analyzed and their characteristics are described in Table 1. There were no significant differences between the cohorts with regards to age, body mass index (BMI), tumor size, tumor type, tumor biology, or the proportion of patients with SLN metastasis. The SPIO injections were well-tolerated and no adverse effects were reported in the groups.

Table 1. Patient and tumor characteristics.

\begin{tabular}{|c|c|c|c|c|c|}
\hline & & $\begin{array}{l}\text { Nordic Trial } \\
\quad(2 \mathrm{~mL})\end{array}$ & $\begin{array}{l}\text { Sentidose Trial } \\
(1.5 \mathrm{~mL})\end{array}$ & $\begin{array}{c}\text { Sentidose Trial } \\
(1.0 \mathrm{~mL})\end{array}$ & $p$-Value \\
\hline \multicolumn{2}{|c|}{ Patients, $n=534$} & 206 & 163 & 165 & n.a. \\
\hline \multicolumn{2}{|c|}{ Age, years (mean) } & 62 & 64 & 63 & $0.101 *$ \\
\hline \multicolumn{2}{|c|}{ BMI, kg/m² (mean) } & 27.9 & 27.2 & 26.5 & $0.568 *$ \\
\hline \multicolumn{2}{|c|}{ Tumor size, mm (mean) } & 19 & 20 & 20 & 0.751 * \\
\hline \multirow{4}{*}{ Histology } & DCIS & 12 & 9 & 4 & \multirow{4}{*}{$0.694^{\#}$} \\
\hline & IDC & 158 & 122 & 121 & \\
\hline & ILC & 26 & 21 & 28 & \\
\hline & Other & 10 & 11 & 12 & \\
\hline \multirow{3}{*}{ ER-status } & Positive & 170 & 138 & 145 & \multirow{3}{*}{$0.831^{\#}$} \\
\hline & Negative & 20 & 13 & 16 & \\
\hline & Missing & 16 & 12 & 4 & \\
\hline \multirow{3}{*}{ HER2-status } & Positive & 20 & 9 & 16 & \multirow{3}{*}{$0.217^{\#}$} \\
\hline & Negative & 172 & 142 & 144 & \\
\hline & Missing & 14 & 12 & 5 & \\
\hline \multicolumn{2}{|c|}{ Ki67 (\%) (mean) } & 26.6 & 23.5 & 25.2 & 0.349 * \\
\hline \multicolumn{2}{|c|}{ No. patients with metastasis } & 54 & 33 & 29 & $0.120^{\#}$ \\
\hline \multirow{2}{*}{$\begin{array}{l}\text { Previous ipsilateral } \\
\text { breast surgery }\end{array}$} & Yes & 17 & 0 & 0 & $<0.001^{\#}$ \\
\hline & No & 189 & 163 & 165 & \\
\hline \multirow{2}{*}{$\begin{array}{l}\text { Previous ipsilateral } \\
\text { axillary surgery }\end{array}$} & Yes & 3 & 0 & 0 & \multirow{2}{*}{$0.114^{\#}$} \\
\hline & No & 203 & 163 & 165 & \\
\hline \multirow{2}{*}{ Type of surgery } & $\mathrm{BCT}$ & 154 & 130 & 141 & \multirow{2}{*}{$0.038^{\#}$} \\
\hline & Mastectomy & 52 & 33 & 24 & \\
\hline \multirow{3}{*}{ SPIO Injection site } & Peri-/Sub-areolar & 198 & 157 & 68 & \multirow{3}{*}{$<0.001^{\#}$} \\
\hline & Peritumoral & 3 & 6 & 97 & \\
\hline & Missing & 5 & 0 & 0 & \\
\hline
\end{tabular}

BCT: breast conserving therapy, BMI: body mass index, DCIS: ductal cancer in situ, ER: estrogen receptor, HER2: Human epithelial growth factor receptor type 2, IDC: invasive ductal cancer, ILC: invasive lobular cancer, n.a.: not assessed, SPIO: superparamagnetic iron oxide. *: analysis of variance (ANOVA), : Pearson's $\chi^{2}$ test.

\subsection{Sentinel Lymph Node Identification-Per Patient}

The overall magnetic SLN detection rate per patient was $97.6 \%$ in the Nordic trial, $97.5 \%$ in the $1.5 \mathrm{~mL}$ cohort and $100 \%$ in the $1.0 \mathrm{~mL}$ cohort $(p=0.110)$. Multivariable regression analysis showed a trend for significance for previous breast surgery with regards to the per-patient SLN magnetic detection rate at $>0$ magnetic tracer signal cut-off $(b=5.435$, 95\% confidence interval (CI) 0.925, 31.935; $p=0.061$ ), and significance for previous breast surgery at $>20$ cut-off $(b=6.957,95 \%$ CI $1.552,31.192, p=0.011)$. The detection rate of pathologically positive SLNs (malignancy rate) was $96.3 \%$ in the Nordic trial, $97 \%$ in the $1.5 \mathrm{~mL}$ cohort and $100 \%$ in the $1.0 \mathrm{~mL}$ cohort $(p=0.796)$. The SPIO-RI concordance rates 
were $98 \%$ vs. $97.8 \%$ vs. $100 \%$, respectively $(p=0.115)$. The concordance rate with regards to patients with pathologically positive SLNs was $98 \%$ in the Nordic trial, $97 \%$ in the $1.5 \mathrm{~mL}$ cohort and $100 \%$ in the $1.0 \mathrm{~mL}$ cohort $(p=1.0)$ (see Table 2 ).

Table 2. Sentinel lymph node identification-per patient.

\begin{tabular}{|c|c|c|c|c|}
\hline$n=534$ & $\begin{array}{c}\text { Nordic Trial } \\
(2 \mathrm{~mL}) n=206\end{array}$ & $\begin{array}{l}\text { Sentidose Trial } \\
(1.5 \mathrm{~mL}) n=163\end{array}$ & $\begin{array}{l}\text { Sentidose Trial } \\
(1.0 \mathrm{~mL}) n=165\end{array}$ & $p$-Value \\
\hline \multicolumn{5}{|l|}{ SPIO SLN detection rate (\%) } \\
\hline If magnetic signal > 0 & 97.6 & 97.5 & 100 & $0.110 *$ \\
\hline If magnetic signal > 20 & 97.1 & 95.7 & 100 & $0.016^{*}$ \\
\hline \multicolumn{5}{|l|}{$\begin{array}{l}\text { SPIO SLN detection rate, } \\
\text { malignancy }(\%)\end{array}$} \\
\hline If magnetic signal > 0 & 96.3 & 97.0 & 100 & $0.796^{\#}$ \\
\hline If magnetic signal > 20 & 94.4 & 97.0 & 100 & $0.693^{\#}$ \\
\hline \multicolumn{5}{|l|}{$\begin{array}{l}\text { SPIO-RI SLN } \\
\text { concordance }(\%)\end{array}$} \\
\hline If magnetic signal $>0$ & 98.0 & 97.8 & 100 & $0.115^{\#}$ \\
\hline If magnetic signal > 20 & 97.5 & 93.8 & 100 & $0.265^{\#}$ \\
\hline \multicolumn{5}{|l|}{$\begin{array}{l}\text { SPIO-RI SLN concordance, } \\
\text { malignancy }(\%)\end{array}$} \\
\hline If magnetic signal $>0$ & 98.1 & 97 & 100 & $1.000^{\#}$ \\
\hline If magnetic signal > 20 & 96.2 & 100 & 100 & $1.000 \#$ \\
\hline
\end{tabular}

\subsection{Sentinel Lymph Node Identification-Per Node}

The nodal detection rate was $93.3 \%$ in the Nordic trial, $85.6 \%$ in the $1.5 \mathrm{~mL}$ cohort and $97 \%$ in the $1.0 \mathrm{~mL}$ cohort $(p=<0.001)$. The mean number of SLNs retrieved in the three cohorts was 1.83 vs. 1.85 vs. $2.18(p=0.003)$. The SPIO malignancy rate per node was $93.8 \%$ in the Nordic trial, $79.5 \%$ in the $1.5 \mathrm{~mL}$ cohort and $100 \%$ in the $1.0 \mathrm{~mL}$ cohort. In multivariable analysis, preoperative injection (1-7 days) was associated with the retrieval of more SLNs and a higher nodal detection rate. Detailed per-node results are reported in Tables 3 and 4 .

\subsection{Effect of Injection Site and Injection Timing on SLN Detection}

For a magnetic signal > 0, SLN detection after a periareolar injection was $97.9 \%$ vs. $100 \%$ after a peritumoral injection $(p=0.301)$, and for a magnetic signal $>20,96.9 \%$ vs $100 \%$, respectively ( $p=0.174$ ). Regarding injection timing, a preoperative injection ( 1 to 7 days before surgery) was found to enhance SLN for a magnetic signal $>0$ (100\% vs. 97.6\% for perioperative injection, $p=0.063$ ). Looking into magnetic signal $>20$, the difference was larger in favor of preoperative injection (100\% vs. $96.5 \%, p=0.012)$. This difference was retained in multivariable logistic regression. Regarding the number of SLNs retrieved, multivariable linear regression showed that periareolar injection was linked with a trend of retrieving less SLNs $(b=0.215,95 \%$ CI $-0.036,0.465, p=0.093)$, but the result was not statistically significant.

\subsection{Skin Staining}

The incidence and size of SPIO staining at 6 months in women undergoing breast conserving therapy (BCT) were not significantly different between the $1.5 \mathrm{~mL}$ cohort and the 1.0 mL cohort: $25.6 \%(33 / 129)$ vs. $18.4 \%(26 / 141)(p=0.15)$, with mean sizes of 13.4 
and $11.2 \mathrm{~cm}^{2}(p=0.16)$. In multivariable logistic regression, a peritumoral injection was associated with less skin staining.

Table 3. Sentinel lymph node identification-per node.

\begin{tabular}{|c|c|c|c|c|}
\hline$n=534$ & $\begin{array}{c}\text { Nordic Trial } \\
(2 \mathrm{~mL}) n=206\end{array}$ & $\begin{array}{l}\text { Sentidose Trial } \\
(1.5 \mathrm{~mL}) n=163\end{array}$ & $\begin{array}{l}\text { Sentidose Trial } \\
(1.0 \mathrm{~mL}) n=165\end{array}$ & $p$-Value \\
\hline \multicolumn{5}{|l|}{ No. SPIO SLNs (mean) } \\
\hline If magnetic signal $>0$ & 1.83 & 1.85 & 2.18 & $0.003 *$ \\
\hline If magnetic signal > 20 & 1.80 & 1.83 & 2.18 & $0.016^{*}$ \\
\hline \multicolumn{5}{|l|}{ Nodal detection rate (\%) } \\
\hline If magnetic signal $>0$ & 93.3 & 85.6 & 97 & $<0.001$ \\
\hline If magnetic signal > 20 & 92 & 84.9 & 97 & $<0.001$ \\
\hline \multicolumn{5}{|l|}{$\begin{array}{c}\text { No. SPIO SLNs, } \\
\text { malignancy (mean) }\end{array}$} \\
\hline If magnetic signal $>0$ & 1.11 & 0.8 & 1.18 & $<0.001$ * \\
\hline If magnetic signal > 20 & 1.11 & 0.8 & 1.18 & $<0.001$ * \\
\hline \multicolumn{5}{|l|}{$\begin{array}{l}\text { Nodal detection rate, } \\
\text { malignancy }(\%)\end{array}$} \\
\hline If magnetic signal $>0$ & 93.8 & 79.5 & 100 & $0.005^{\#}$ \\
\hline If magnetic signal > 20 & 93.8 & 79.5 & 100 & $0.005^{\#}$ \\
\hline \multicolumn{5}{|l|}{$\begin{array}{c}\text { Nodal SPIO-RI } \\
\text { concordance (\%) }\end{array}$} \\
\hline If magnetic signal $>0$ & 92.3 & 87.6 & 97.1 & $<0.001^{\#}$ \\
\hline If magnetic signal > 20 & 100 & 87.2 & 96.8 & $<0.001^{\#}$ \\
\hline \multicolumn{5}{|l|}{$\begin{array}{l}\text { Nodal SPIO-RI } \\
\text { concordance, } \\
\text { malignancy }(\%)\end{array}$} \\
\hline If magnetic signal $>0$ & 96.3 & 79.4 & 100 & $0.009^{\#}$ \\
\hline If magnetic signal > 20 & 100 & 74.4 & 100 & $<0.001^{\#}$ \\
\hline
\end{tabular}


Table 4. Cross-tabulation-Sentinel lymph node detection-in total numbers/cohort.

\begin{tabular}{|c|c|c|c|c|c|c|c|c|c|}
\hline \multicolumn{10}{|c|}{ Nordic Trial Cohort } \\
\hline \multicolumn{5}{|c|}{ Magnetic signal > 0} & \multicolumn{5}{|c|}{ Magnetic signal > 20} \\
\hline \multicolumn{5}{|c|}{ Radioisotope } & & \multicolumn{4}{|c|}{ Radioisotope } \\
\hline & & Yes & No & Total & & & Yes & No & Total \\
\hline \multirow{2}{*}{ SPIO } & Yes & 368 & 8 & 376 & \multirow{2}{*}{ SPIO } & Yes & 323 & 48 & 371 \\
\hline & No & 6 & 22 & 26 & & No & 27 & 4 & 31 \\
\hline & Total & 372 & 30 & 402 & & Total & 350 & 52 & 402 \\
\hline \multicolumn{10}{|c|}{ SentiDose $1.5 \mathrm{~mL}$ cohort } \\
\hline \multicolumn{5}{|c|}{ Magnetic signal $>0$} & \multicolumn{5}{|c|}{ Magnetic signal > 20} \\
\hline \multicolumn{5}{|c|}{ Radioisotope } & & \multicolumn{4}{|c|}{ Radioisotope } \\
\hline & & Yes & No & Total & & & Yes & No & Total \\
\hline \multirow{2}{*}{ SPIO } & Yes & 298 & 0 & 298 & \multirow{2}{*}{ SPIO } & Yes & 275 & 26 & 301 \\
\hline & No & 6 & 47 & 53 & & No & 38 & 12 & 50 \\
\hline & Total & 304 & 47 & 351 & & Total & 313 & 38 & 351 \\
\hline \multicolumn{10}{|c|}{ SentiDose $1.0 \mathrm{~mL}$ cohort } \\
\hline \multicolumn{5}{|c|}{ Magnetic signal >0 } & \multicolumn{5}{|c|}{ Magnetic signal > 20} \\
\hline \multicolumn{5}{|c|}{ Radioisotope } & & \multicolumn{4}{|c|}{ Radioisotope } \\
\hline & & Yes & No & Total & & & Yes & No & Total \\
\hline \multirow{3}{*}{ SPIO } & Yes & 300 & 59 & 359 & \multirow{2}{*}{ SPIO } & Yes & 299 & 61 & 360 \\
\hline & No & 9 & 3 & 12 & & No & 10 & 1 & 11 \\
\hline & Total & 309 & 62 & 371 & & Total & 309 & 62 & 371 \\
\hline
\end{tabular}

\section{Discussion}

In the largest patient dataset to date, lowering SPIO volume to $1.0-1.5 \mathrm{~mL}$ did not affect SLN detection. The SLN detection rate per patient was at least $96.7 \%$, constantly comparable to RI $\pm \mathrm{BD}$ and unaffected by SPIO dose, timeframe and injection site. Moreover, different doses, injection timeframes and sites resulted in equally high SPIO-RI concordance rates.

These findings are consistent with recent results by Alvarado et al. [19] and Rubio et al. [20]. In these studies, however, SPIO was administered intraoperatively and injected in the subareolar area. The present results provide more evidence that, not only can a smaller dose be equally efficient, but also that an extended injection timeframe in the preoperative period might enhance the detection rate and SLN retrieval. It seems that preoperative injection allows for higher SPIO concentration in the SLN, which was demonstrated in the present study by the fact that there were no "low-signal" SLNs in this patient group and that brown coloring of the SLN was more intense. In addition, not only were there more SLNs retrieved, but the nodal detection rate was also higher, indicating that preoperative SPIO injection allows for accumulation in the SLNs, whereas SPIO in the lymphatics, which may produce a "magnetic background", is washed away to the circulation. Whilst the mean number of SLNs retrieved in patients injected preoperatively was 2.2, SPIO-RI nodal concordance was as high as $97 \%$, demonstrating that there is no risk that the magnetic tracer would yield an unnecessary increase in the mean number of SLNs excised.

In previous studies from our group, results have shown that a preoperative injection of SPIO can be extended to more than 30 days before surgery with equally high SLN detection rates $[14,17,24]$, but this had not been tested with a reduced SPIO dose. It is now clearer that timeframe is probably more important than the dose itself. In this context, SPIO is a highly effective tracer because it yields very high detection rates, but at the same time provides 
flexibility and ease of administration, as it can be injected both intraoperatively and also at the outpatient clinic, sparing intraoperative time and resources and facilitating logistics.

Skin staining after SPIO injection is a concern, although several reports have shown that most patients do not consider it a problem [14,17,20]. In the SentiMagIC study [19], skin discoloration after a $2.0 \mathrm{~mL}$ subareolar injection was reported in $15.6 \%$ of patients. However, the proportion of BCS and the time for follow-up were not specified.

In the SUNRISE study by Rubio et al. [20], using subareolar injections in patients who underwent $\mathrm{BCT}$ resulted in staining varying from $59 \%$ in patients who received $1.0 \mathrm{~mL}$ to $83.3 \%$ in patients who received $2.0 \mathrm{~mL}$. In the present results, a deeper, peritumoral injection seems to be associated with less skin staining, consistent with previous findings [14,17], implying that excision of the SPIO-stained injection site reduces the skin staining rate. A peritumoral injection and a smaller SPIO dose might also address the concern that has been reported for postoperative magnetic resonance imaging (MRI) artifacts [25], as the bulk of SPIO is excised with the tumor. Currently, our group is accruing data to specifically address this issue within the prospective POSTMAG MRI trial [26]. Despite that flexibility in injection site in the $1.0 \mathrm{~mL}$ cohort may have not allowed for the formation of two patient cohorts with distinctive characteristics, the study protocol allowed flexibility in the second cohort regarding the injection site, as manufacturer instructions during the study period stated that periareolar injection can be applied intraoperatively, regardless of dose, but peritumoral might require a longer time. At the same time, analysis of other data from our group published elsewhere [17] were in favor of a deeper injection, achieving comparable detection rates and resulting in less skin staining. Those previous conclusions are confirmed in the present results.

The study design did not include patient randomization, which is the standard robust methodological approach [27]. However, given the fact that study participants stemmed from the same reference population and that no differences in baseline patient demographics or tumor data could be demonstrated, implementing randomization would have been highly challenging for logistics in the multicenter setting without necessarily adding much more to the study results [28]. The technique of one-stage IPD meta-analysis was utilized, so as to improve the quality of data and expand the type of analyses that may be performed, thus producing more reliable results than the comparison with aggregate or historical data [29]. In the particular dataset, the homogeneity of study populations and protocols between the Nordic trial and the SentiDose suggests low risk of ecological bias, and within- and across-studies information do not differ substantially [30]. This resulted in a large patient dataset, highly representative of the relevant background population of breast cancer patients. Additionally, the study was performed in diverse clinical settings, including both university and regional hospitals, and breast cancer units that use SPIO routinely or not. This fact reflects a pragmatic value to the applicability of the study results, as they reflect routine practice rather than highly selected cases of patients. On the other hand, less exclusion criteria might have added more to study pragmatism, but that would have, in turn, created more patient subgroups and deviated from the primary aim of the trial, which was to investigate the performance of lower SPIO doses.

In a large patient dataset, it is now shown that a reduction down to half of the stipulated dose is highly effective and that a deeper preoperative injection yields more SLNs while retaining a high SPIO-RI concordance rate and resulting in less skin staining, when injected peritumorally. The use of SPIO in other clinical situations, such as SLN identification and dissection in malignant melanoma [31], prostate cancer [32-34], penile cancer [35] and uterine cancer [36], has been investigated, with interesting implementations.

Regarding breast cancer, the present results build on a substantial body of evidence that renders SPIO a very effective SLN tracer, that should not be considered an alternative to the RI anymore, as the comparable performance, ease of access and flexibility in delivery of care are important properties for clinical routine and implementation in the global setting. In this context, long-term follow-up and more studies to address specific clinical situations is paramount, in order to reach a robust and clinically relevant conclusion. 


\section{Conclusions}

Magtrace ${ }^{\circledR}$ in lower doses $(1.5 \mathrm{~mL}, 1.0 \mathrm{~mL})$ is noninferior for SLN detection in patients with breast cancer compared with Sienna $+{ }^{\circledR}$ and highly concordant with the dual technique. Apart from perioperative administration, it was shown that preoperative peritumoral injection of $1.0 \mathrm{~mL}$ not only facilitated logistics but also increased detection rate and nodal yield, with high concordance with the dual technique with the additional advantage of less skin staining. Magnetic-guided SLN detection not only has the potential to omit isotopebased axillary mapping but preoperative administration allows for novel implementations to meet tailored needs of breast cancer patients.

Author Contributions: Conceptualization, F.W. and A.K.; methodology, F.W. and A.K.; software, A.K.; validation, F.W., A.K. and S.E.; formal analysis, A.K.; investigation, A.-F.H., L.P., C.D.L., E.V.-P., R.O.B., F.N., I.M., F.W., S.E. and A.K.; resources, A.-F.H., L.P., C.D.L., E.V.-P., R.O.B., F.N., I.M., F.W., S.E. and A.K.; data curation, F.W. and A.K.; writing-original draft preparation, A.-F.H.; writingreview and editing, A.-F.H., L.P., C.D.L., E.V.-P., R.O.B., F.N., I.M., F.W., S.E. and A.K.; visualization, A.-F.H.; supervision, F.W., A.K. and S.E.; project administration, F.W. and A.K.; funding acquisition, F.W. All authors have read and agreed to the published version of the manuscript.

Funding: Sysmex Europe GmbH and Endomagnetics, Cambridge, UK, provided the SentiMag ${ }^{\circledR}$ device and Magtrace ${ }^{\circledR}$ vials for the trial. Institutional grants by Uppsala University and Västmanland Cancer Foundation are acknowledged. The sponsors had no role in study design, collection, analysis or interpretation of the data.

Institutional Review Board Statement: The study was conducted according to the guidelines of the Helsinki Declaration of ethical principles involving human subjects and was approved by Uppsala University regional ethical committee (decision number 2017/063).

Informed Consent Statement: Informed consent was obtained from all subjects involved in the study.

Data Availability Statement: The data presented in this study are available on request from the corresponding author. The data are not publicly available due to ethical considerations and data regulations.

Conflicts of Interest: The authors declare no conflict of interest.

\section{References}

1. Veronesi, U.; Paganelli, G.; Viale, G.; Luini, A.; Zurrida, S.; Galimberti, V.; Intra, M.; Veronesi, P.; Robertson, C.; Maisonneuve, P.; et al. A randomized comparison of sentinel-node biopsy with routine axillary dissection in breast cancer. N. Engl. J. Med. 2003, 349, 546-553. [CrossRef]

2. Del Bianco, P.; Zavagno, G.; Burelli, P.; Scalco, G.; Barutta, L.; Carraro, P.; Pietrarota, P.; Meneghini, G.; Morbin, T.; Tacchetti, G.; et al. Morbidity comparison of sentinel lymph node biopsy versus conventional axillary lymph node dissection for breast cancer patients: Results of the sentinella-GIVOM Italian randomised clinical trial. Eur. J. Surg. Oncol. 2008, 34, 508-513. [CrossRef]

3. Ashikaga, T.; Krag, D.N.; Land, S.R.; Julian, T.B.; Anderson, S.J.; Brown, A.M.; Skelly, J.M.; Harlow, S.P.; Weaver, D.L.; Mamounas, E.P.; et al. Morbidity results from the NSABP B-32 trial comparing sentinel lymph node dissection versus axillary dissection. J. Surg. Oncol. 2010, 102, 111-118. [CrossRef]

4. Lucci, A.; McCall, L.M.; Beitsch, P.D.; Whitworth, P.W.; Reintgen, D.S.; Blumencranz, P.W.; Leitch, M.; Saha, S.; Hunt, K.K.; Giuliano, A.E. Surgical complications associated with sentinel lymph node dissection (SLND) plus axillary lymph node dissection compared with SLND alone in the American College of Surgeons Oncology Group Trial Z0011. J. Clin. Oncol. 2007, 25, 3657-3663. [CrossRef] [PubMed]

5. Mansel, R.E.; Fallowfield, L.; Kissin, M.; Goyal, A.; Newcombe, R.G.; Dixon, J.M.; Yiangou, C.; Horgan, K.; Bundred, N.; Monypenny, I.; et al. Randomized multicenter trial of sentinel node biopsy versus standard axillary treatment in operable breast cancer: The ALMANAC Trial. J. Natl. Cancer Inst. 2006, 98, 599-609. [CrossRef] [PubMed]

6. Giuliano, A.E.; Ballman, K.V.; McCall, L.; Beitsch, P.D.; Brennan, M.B.; Kelemen, P.R.; Ollila, D.W.; Hansen, N.M.; Whitworth, P.W.; Blumencranz, P.W.; et al. Effect of Axillary Dissection vs No Axillary Dissection on 10-Year Overall Survival Among Women With Invasive Breast Cancer and Sentinel Node Metastasis: The ACOSOG Z0011 (Alliance) Randomized Clinical Trial. JAMA 2017, 318, 918-926. [CrossRef] [PubMed]

7. Krag, D.N.; Anderson, S.J.; Julian, T.B.; Brown, A.M.; Harlow, S.P.; Costantino, J.P.; Ashikaga, T.; Weaver, D.L.; Mamounas, E.P.; Jalovec, L.M.; et al. Sentinel-lymph-node resection compared with conventional axillary-lymph-node dissection in clinically node-negative patients with breast cancer: Overall survival findings from the NSABP B-32 randomised phase 3 trial. Lancet Oncol. 2010, 11, 927-933. [CrossRef] 
8. Veronesi, U.; Paganelli, G.; Viale, G.; Luini, A.; Zurrida, S.; Galimberti, V.; Intra, M.; Veronesi, P.; Maisonneuve, P.; Gatti, G.; et al. Sentinel-lymph-node biopsy as a staging procedure in breast cancer: Update of a randomised controlled study. Lancet Oncol. 2006, 7, 983-990. [CrossRef]

9. Ahmed, M.; Purushotham, A.D.; Douek, M. Novel techniques for sentinel lymph node biopsy in breast cancer: A systematic review. Lancet Oncol. 2014, 15, e351-e362. [CrossRef]

10. Bézu, C.; Coutant, C.; Salengro, A.; Daraï, E.; Rouzier, R.; Uzan, S. Anaphylactic response to blue dye during sentinel lymph node biopsy. Surg. Oncol. 2011, 20, e55-e59. [CrossRef]

11. Albo, D.; Wayne, J.D.; Hunt, K.K.; Rahlfs, T.F.; Singletary, S.E.; Ames, F.C.; Feig, B.W.; Ross, M.I.; Kuerer, H.M. Anaphylactic reactions to isosulfan blue dye during sentinel lymph node biopsy for breast cancer. Am. J. Surg. 2001, 182, 393-398. [CrossRef]

12. Teshome, M.; Wei, C.; Hunt, K.K.; Thompson, A.; Rodriguez, K.; Mittendorf, E.A. Use of a Magnetic Tracer for Sentinel Lymph Node Detection in Early-Stage Breast Cancer Patients: A Meta-analysis. Ann. Surg. Oncol. 2016, 23, 1508-1514. [CrossRef] [PubMed]

13. Karakatsanis, A.; Christiansen, P.M.; Fischer, L.; Hedin, C.; Pistioli, L.; Sund, M.; Rasmussen, N.R.; Jörnsgård, H.; Tegnelius, D.; Eriksson, S.; et al. The Nordic SentiMag trial: A comparison of super paramagnetic iron oxide (SPIO) nanoparticles versus $\mathrm{Tc}(99)$ and patent blue in the detection of sentinel node (SN) in patients with breast cancer and a meta-analysis of earlier studies. Breast Cancer Res Treat. 2016, 157, 281-294. [CrossRef] [PubMed]

14. Karakatsanis, A.; Daskalakis, K.; Stalberg, P.; Olofsson, H.; Andersson, Y.; Eriksson, S.; Bergkvist, L.; Wärnberg, F. Superparamagnetic iron oxide nanoparticles as the sole method for sentinel node biopsy detection in patients with breast cancer. Br. J. Surg. 2017, 104, 1675-1685. [CrossRef]

15. Ghilli, M.; Carretta, E.; Di Filippo, F.; Battaglia, C.; Fustaino, L.; Galanou, I.; Di Filippo, S.; Rucci, P.; Fantini, M.P.; Roncella, M. The superparamagnetic iron oxide tracer: A valid alternative in sentinel node biopsy for breast cancer treatment. Eur. J. Cancer Care 2017, 26. [CrossRef]

16. Rubio, I.T.; Diaz-Botero, S.; Esgueva, A.; Rodriguez, R.; Cortadellas, T.; Cordoba, O.; Espinosa-Bravo, M. The superparamagnetic iron oxide is equivalent to the Tc99 radiotracer method for identifying the sentinel lymph node in breast cancer. Eur. J. Surg. Oncol. 2015, 41, 46-51. [CrossRef]

17. Warnberg, F.; Stigberg, E.; Obondo, C.; Olofsson, H.; Abdsaleh, S.; Warnberg, M.; Karakatsanis, A. Long-Term Outcome After Retro-Areolar Versus Peri-Tumoral Injection of Superparamagnetic Iron Oxide Nanoparticles (SPIO) for Sentinel Lymph Node Detection in Breast Cancer Surgery. Ann. Surg. Oncol. 2019, 26, 1247-1253. [CrossRef] [PubMed]

18. Karakatsanis, A.; Olofsson, H.; Stalberg, P.; Bergkvist, L.; Abdsaleh, S.; Warnberg, F. Simplifying Logistics and Avoiding the Unnecessary in Patients With Breast Cancer Undergoing Sentinel Node Biopsy. A Prospective Feasibility Trial of the Preoperative Injection of Super Paramagnetic Iron Oxide Nanoparticles. Scand. J. Surg. 2018, 107, 130-137. [CrossRef]

19. Alvarado, M.D.; Mittendorf, E.A.; Teshome, M.; Thompson, A.M.; Bold, R.J.; Gittleman, M.A.; Beitsch, P.D.; Blair, S.L.; Kivilaid, K.; Harmer, Q.J.; et al. SentimagIC: A Non-inferiority Trial Comparing Superparamagnetic Iron Oxide Versus Technetium-99m and Blue Dye in the Detection of Axillary Sentinel Nodes in Patients with Early-Stage Breast Cancer. Ann. Surg. Oncol. 2019, 26, 3510-3516. [CrossRef]

20. Rubio, I.T.; Rodriguez-Revuelto, R.; Espinosa-Bravo, M.; Siso, C.; Rivero, J.; Esgueva, A. A randomized study comparing different doses of superparamagnetic iron oxide tracer for sentinel lymph node biopsy in breast cancer: The SUNRISE study. Eur. J. Surg. Oncol. 2020, 46, 2195-2201. [CrossRef] [PubMed]

21. Tudur Smith, C.; Marcucci, M.; Nolan, S.J.; Iorio, A.; Sudell, M.; Riley, R.; Rovers, M.M.; Williamson, P.R. Individual participant data meta-analyses compared with meta-analyses based on aggregate data. Cochrane Database Syst. Rev. 2016, 9, Mr000007. [CrossRef]

22. von Elm, E.; Altman, D.G.; Egger, M.; Pocock, S.J.; Gøtzsche, P.C.; Vandenbroucke, J.P. The Strengthening the Reporting of Observational Studies in Epidemiology (STROBE) statement: Guidelines for reporting observational studies. Lancet 2007, 370 , 1453-1457. [CrossRef]

23. Stewart, L.A.; Clarke, M.; Rovers, M.; Riley, R.D.; Simmonds, M.; Stewart, G.; Tierney, J.F. Preferred Reporting Items for Systematic Review and Meta-Analyses of individual participant data: The PRISMA-IPD Statement. JAMA 2015, 313, 1657-1665. [CrossRef]

24. Karakatsanis, A.; Hersi, A.F.; Pistiolis, L.; Olofsson Bagge, R.; Lykoudis, P.M.; Eriksson, S.; Wärnberg, F.; Nagy, G.; Mohammed, I.; Sundqvist, M.; et al. Effect of preoperative injection of superparamagnetic iron oxide particles on rates of sentinel lymph node dissection in women undergoing surgery for ductal carcinoma in situ (SentiNot study). Br. J. Surg. 2019, 106, 720-728. [CrossRef]

25. Krischer, B.; Forte, S.; Niemann, T.; Kubik-Huch, R.A.; Leo, C. Feasibility of breast MRI after sentinel procedure for breast cancer with superparamagnetic tracers. Eur. J. Surg. Oncol. 2018, 44, 74-79. [CrossRef] [PubMed]

26. Karakatsanis, A. Postoperative Breast Mri in Patients Undergoing Sentinel Node Biopsy Using Super Paramagnetic Iron Oxide Nanoparticles, 16 January 2018. Available online: http:/ / www.isrctn.com/ISRCTN85167182 (accessed on 2 October 2020).

27. Yu, J.; Chen, W.; Chen, S.; Jia, P.; Su, G.; Li, Y.; Sun, X. Design, Conduct, and Analysis of Surgical Randomized Controlled Trials: A Cross-sectional Survey. Ann. Surg. 2019, 270, 1065-1069. [CrossRef]

28. Riley, R.D.; Debray, T.P.A.; Fisher, D.; Hattle, M.; Marlin, N.; Hoogland, J.; Gueyffier, F.; Staessen, J.A.; Wang, J.; Moons, K.G.M.; et al. Individual participant data meta-analysis to examine interactions between treatment effect and participant-level covariates: Statistical recommendations for conduct and planning. Stat. Med. 2020, 39, 2115-2137. [CrossRef] 
29. Stewart, L.A.; Tierney, J.F. To IPD or not to IPD? Advantages and disadvantages of systematic reviews using individual patient data. Eval. Health Prof. 2002, 25, 76-97. [CrossRef]

30. Hua, H.; Burke, D.L.; Crowther, M.J.; Ensor, J.; Tudur Smith, C.; Riley, R.D. One-stage individual participant data meta-analysis models: Estimation of treatment-covariate interactions must avoid ecological bias by separating out within-trial and across-trial information. Stat. Med. 2017, 36, 772-789. [CrossRef]

31. The Use of Magtrace ${ }^{\circledR} /$ Sentimag ${ }^{\circledR}$ in Sentinel Node Biopsy for Malignant Melanoma. The Magmen Study. Available online: https: / / ClinicalTrials.gov / show / NCT03898687 (accessed on 4 October 2020).

32. Winter, A.; Engels, S.; Goos, P.; Süykers, M.C.; Gudenkauf, S.; Henke, R.P.; Wawroschek, F. Accuracy of Magnetometer-Guided Sentinel Lymphadenectomy after Intraprostatic Injection of Superparamagnetic Iron Oxide Nanoparticles in Prostate Cancer: The SentiMag Pro II Study. Cancers 2019, 12, 32. [CrossRef]

33. Staník, M.; Macík, D.; Čapák, I.; Marečková, N.; Lžíčařová, E.; Doležel, J. Sentinel lymph node dissection in prostate cancer using superparamagnetic particles of iron oxide: Early clinical experience. Int. Urol. Nephrol. 2018, 50, 1427-1433. [CrossRef] [PubMed]

34. Czarniecki, M.; Pesapane, F.; Wood, B.J.; Choyke, P.L.; Turkbey, B. Ultra-small superparamagnetic iron oxide contrast agents for lymph node staging of high-risk prostate cancer. Transl. Androl. Urol. 2018, 7 (Suppl. 4), S453-S461. [CrossRef] [PubMed]

35. Winter, A.; Kowald, T.; Engels, S.; Wawroschek, F. Magnetic Resonance Sentinel Lymph Node Imaging and Magnetometer-Guided Intraoperative Detection in Penile Cancer, using Superparamagnetic Iron Oxide Nanoparticles: First Results. Urol. Int. 2020, 104, 177-180. [CrossRef] [PubMed]

36. Murakami, K.; Kotani, Y.; Suzuki, A.; Takaya, H.; Nakai, H.; Matsuki, M.; Sato, T.; Mandai, M.; Matsumura, M. Superparamagnetic iron oxide as a tracer for sentinel lymph node detection in uterine cancer: A pilot study. Sci. Rep. 2020, 10, 7945. [CrossRef] 